form of magnetic separation was coming to the front. For a long time the method was confined to minerals that were naturally or artificially magnetic in the everyday acceptance of that word, that is to say, were capable of being attracted by an ordinary horse-shoe magnet. Faraday had discovered so far back as 1845 that numerous bodies, not magnetic in this ordinary sense, were nevertheless affected by powerful magnetic fields, but it was not until 1896 that this principle was applied to the separation of minerals by J. P. Wetherill; he succeeded in separating a series of minerals, all very feebly magnetic, from the somewhat more feebly magnetic zinc oxide and other zinc ores of New Jersey by the use of very powerful magnetic fields, produced by means of electromagnets with wedgeshaped pole-pieces, and since his original invention this principle (the magnetic separation of non-magnetic material, as it is sometimes called) has found an extended application, one of the most recent being the magnetic concentration of specular hæmatite by the Edison deflection method, using pole-pieces of the Wetherill type. Such separations as that of wolfram from tinstone, of raw spathic ore from zinc blende, of garnets from silver ore, which are necessary before any rational metallurgical treatment of the ores is possible, but which offer insuperable difficulties to the ordinary methods of dressing, have been rendered possible by the adoption of the Wetherill principle, and I see no reason to doubt but that it will find still more extended application in the future. I may point out that no successful wet separator for feebly magnetic minerals has yet been devised; this is a problem presenting numerous difficulties, but probably quite capable of solution, and at the same time very well worth solving.

Magnetic separation, though so comparatively novel, has already been extensively applied, the largest installations being naturally those for the treatment of iron ores. At the present moment the output of high-grade magnetite concentrate, produced by this process, in Sweden cannot fall far short of half a million tons per annum, and in Norway active preparations are in progress for work on a much larger scale at Dunderland, Salangen, Ofoten, and Sydvaranger, from which a yearly output of fully two millions of tons of high-class iron concentrates is expected.

Attempts to utilise other properties of minerals for their separation may be said to belong wholly to the present century. Thus Messrs. Blake and Morscher in rgor, and Mr. Negreanu in I902, have attempted to use electrostatic methods, depending upon the variations in the electrification of minerals due to their varying electric conductivities; the former of these two methods has been used with success for the dressing of blende in the United States.

Finally, the difference in surface tension has been employed in Elmore's oil separation process, in the various flotation processes, devised since the discovery of the principle by C. V. Potter in I90I, and applied to the very intractable zinc-lead ores of the Broken Hill district of New South Wales, and finally in the Elmore vacuum process. All these processes seem to depend upon the differential adhesive force, with which water, oil, or gas cling to the surface of different minerals. These methods are still in their infancy, and the underlying principles cannot yet be said to be properly understood, but already they promise to be of great value in recovering valuable material from slimes that are not amenable to any other mode of treatment. particularly for treating those intimate mixtures of zinc blende and galena that have for so long defied the ingenuity of both miners and metallurgists. There are grounds for hoping that many of the problems that have hitherto baffled the ore-dresser may be solved by some application of these modern methods.

\section{SCIENCE AND INDUSTRY.}

A SERIES of articles has appeared in the Revue scientifique (May 18 and July 13, 1907; February 22, 1908) comparing the teaching of technical chemistry in France with the instruction given in the same subject in other countries. The last article is of special interest as presenting a French view of the relation subsisting between science and industry in our own country. After describing in detail the excellent organisation of scientific education in Germany, Belgium, and Switzerland, and emphasising the closeness of the union existing in these countries between the manufacturer and the man of science, it is stated that the system of technical education adopted in England presents no feature worthy of commendation.

The English manufacturer fails to realise how much he may profit from the assistance of pure science:"l'industriel anglais paraît ou veut ignorer le chimiste de carrière qui vient à lui avec un bagage scientifique; son but étant de produire 'beaucoup et à bon marché' il lui suffit quand il remarque un ouvrier plus intelligent et plus perfectible que ses camarades de l'envoyer aux écoles du soir, prendre un semblant d'instruction théorique et cela sur la seule partie de la chimie qui peut intéresser son métier." The many technical colleges under the control of municipal authorities in this country do not aim at producing highly trained "chemists" in the scientific sense of the word, but waste their resources in providing evening classes for workmen and artisans, and in imparting the rudiments of science to boys from the primary schools.

The university colleges, on the other hand, with the exception of the Central Technical College, provide only a training in pure chemistry. Until science and industry become more intimately united in this country it is predicted that the technical schools will go on producing merely good workmen and the universities men who are unable to investigate practical problems or apply discoveries made in the laboratory on an industrial scale.

It would appear that the chemist is as little appreciated in France as in our own country, and it is pertinently asked whether this is not due to his lack of "general culture "which prevents him from acquiring the broad ideas necessary for the initiation or development of important enterprises. The same question no doubt may be asked of the chemists in this country, but whatever be the answer there is no doubt that, for the proper development of our industry in the near future, a closer union between the industrialist and the chemist is vitally necessary.

\section{UNIVERSITY AND EDUCATIONAL INTELLIGENCE.}

CAMBridge.-The board of managers of the Arnold Gerstenberg studentship gives notice that a studentship will be offered for competition in the Michaelmas term of Igog. The competition will be open to men and women who have obtained honours in part i. or part ii. of the natural sciences tripos, and whose first term of residence was not earlier than the Michaelmas term of 1903. The studentship, which will be of the annual value of nearly 9ol., will be tenable for two years.

The Linacre lecture will be delivered by Dr. W. Osler, F.R.S., on Wednesday, May 6 , in the lecture-room of anatomy and physiology, New Museums. The subject of the lecture will be "Thomas Linacre, his Life and Works."

It is proposed to grant the use of the Senate House on May 15 for a meeting of the members of the University to be addressed by Mr. Haldane, Secretary of State for War, in the explanation of his scheme in connection with the training of officers for war.

Part i. of the natural sciences tripos will commence on Monday, May 25, and part ii. on Wednesday, May 27 . The number of entries for the two parts is about two hundred and twenty.

GLASGOW.-Among the recipients of the honorary degree of Doctor of Laws on Commemoration Day, April 22, were several distinguished by their scientific attainments. In the afternoon a portrait of Prof. M'Kendrick was presented to the University, with the sum of $45 \mathrm{ol}$. for the equipment of a laboratory of experimental psychology in the new physiological buildings, in honour of Prof. M'Kendrick's thirty years' service to the University as professor of physiology. In presenting the representatives of science for the degrees, Prof. Gloag, dean of the faculty of law, made the following references to their work:-

MR. G. T. BEILBY, F.R.S., chairman of the governors of the Giasgow and West of Scotland Technical College.The present head of the Glasgow and West of Scotland Technical College, who is a Fellow of the Royal Society, No. 2009, vor. 77$]$ 